\title{
PENGEMBANGAN PENDIDIKAN KARAKTER \\ MELALUI PELAYANAN BK DI SEKOLAH
}

\author{
Sulma Mafirja \\ sulmamafirja07@gmail.com \\ Jurusan Bimbingan dan Konseling Program Pascasarjana \\ Universitas Negeri Semarang \\ Hj Sa'Adah \\ Jurusan Bimbingan dan Konseling Program Pascasarjana \\ Universitas Negeri Semarang
}

\begin{abstract}
ABSTRAK
Pendidikan karakter merupakan salah satu gerakan pendidikan di sekolah untuk memperkuat karakter siswa melalui harmonisasi olah hati (etika), olah rasa (estetika), olah pikiran (literasi), dan olah raga (kinesteti) dengan dukungan melibatkan publik dan kerja sama antar sekolah, keluarga, dan masyarakat. Sementara layanan bimbingan dan konseling merupakan salah satu program layanan yang turut andil dalam pelaksanaan program di sekolah. Sehingga diharapkan implementasi penguatan pendidikan karakter melalui pelayanan BK di sekolah dapat dilaksanakan dan diterapkan dengan efektif dan efesian, agar dapat mencapai tujuan yang lebih optimal bagi perkembangan nilai-nilai karakter yang ada pada peserta didik.
\end{abstract}

Kata Kunci: Pendidikan Karakter, Layanan Bimbingan dan Konseling

\section{PENDAHULUAN}

Pendidikan merupakan salah satu lembaga pendidikan formal yang menuntut akan terlaksananya seluruh program yang ada di sekolah demi tercapainya tujuan dari pendidikan itu sendiri. Selain itu, pendidikan formal atau lebih di kenal dengan sistem persekolahan, mempunyai peranan yang amat menentukan perkembangan potensi manuia secara maksimal, sehingga manusia itu memiliki ketajaman respon terhadap lingkungan, keterampilan, ehat dan berkehidupan yang baik, koperatif, mempunyai motivai yang tinggi untuk berprestasi, mampu berkompetensi, toleran, dapat menghargai pendapat orang lain, dan mampu mencapai kebahagian hidup, Akbar (2011:110)

Selanjutnya, tujuan pendidikan nasional menurut UU no 20 Tahun 2003 tentang SIDIKNAS dalam pasal 3 ayat (1) mengembangkan kemampuan dan membentuk watak serta peradaban bangas yang bermartabat dalam rangka mencerdasakan kehidupan bangsa. Sedangkan dalam pasal 3 ayat (2) untuk berkembangnya potensi peserta didik agar menjadi manusia yang beriman dan bertaka kepada Tuhan Yang Maha Esa, berakhlak mulia, sehat, berilmu, cakap, kreatif, mandiri dan menjadi warga Negara yang demokrasi serta bertanggung jawab. 
Pendidikan karakter merupakan gerakan pendidikan di sekolah untuk memperkuat karakter siswa melalui harmonisasi olah hati (etika), olah rasa (estetika), olah pikiran (literasi), dan olah raga (kinesteti) dengan dukungan melibatkan publik dan kerja sama antar sekolah, keluarga, dan masyarakat yang merupakan bagian dari Gerakan Nasional Revolusi Mental (GNMR). Sedangkan menurut Lickona menyatakan bahwa pengertian pendidikan karakter adalah suatu usaha yang disengaja untuk membantu seseorang sehingga ia dapat memahami, memperhatikan, dan melakukan nilai-nilai etika yang inti. Ada 18 butir nilai-nilai pendidikan karakter yaitu, Religius, Jujur, Toleransi, Disiplin, Kerja Keras, Kreatif, Mandiri, Demokratis, Rasa Ingin Tahu, Semangat Kebangsaan, Cinta tanah air, Menghargai prestasi, Bersahabat/ komunikatif, Cinta Damai, Gemar membaca, Peduli lingkungan, Peduli sosial, Tanggung jawab.

Relasi ini menghadirkan kontrol terhadap diri sendiri, terhadap hasrat diri untuk melakukan yang benar terhadap orang lain (Lickona, 1991:50). Selanjutnya dia juga mengatakan bahwa karakter adalah nilai-nilai yang beroperasi dan beraksi untuk merespon situasi dan terdiri dari pengetahuan tentang moral, perasaan moral, dan tingkah laku. Dan juga pendidikan karakter adalah bagaimana nilai-nilai karakter tersebut diproses dalam interaksi pembelajaran agar menjadi kompetensi, keinginan, dan kebiasaan (Akbar, 2011:114).

Fokus penguatan pendidikan karakter lebih kepada struktur program, struktur kurikulum, struktur kegiatan. Yang mana pendidikan karakter juga berbasis tidak hanya pada kelas melainkan juga berbasis pada budaya sekolah dan masyarakat. Dengan demikian, diharapkan pendidikan karakter ini dapat menghasilkan atau menciptakan output yang memang bekerja sesuai dengan 4 dimensi perkembangan. (Kementrian Pendidikan Dan Kebudayaan Indonesia).

Selain itu diharapkan pendidikan karakter ini dapat diimplementasikan dengan menggunakan bantuan dari layanan bimbingan dan konseling. Konselor sekolah adalah guru yang melayani dan memberikan layanan di lembaga pendidikan, menawarkan bantuan konseling bagi siswa untuk mengetahui dan menerima kepribadiannya yang terus berkembang; untuk membuat keputusan dan pilihan mengenai suatu permasalahan yang mana konseli diharapkan mampu; untuk menangani masalahmasalah yang dia temui; untuk mengembangkan kemampuan dan potensi yang dia miliki demi tercapainya aktualisasi diri yang lebih baik. Konselor sekolah umumnya melakukan kegiatan mereka dengan berbagai jenis layanan baik secara individu maupun kelompok, dan di lakukan dengan cara konseling, bimbingan, konsultasi, koordinasi, manajemen kasus, kurikulum bimbingan, perencanaan program, manajemen dan evaluasi (ASCA, 2007; Fitch \& Marshall, 2004; Kuhn 2004; Morrissette, 2000; Paisley \& Mc Mahon, 2001).

Selain diharapkannya peran konselor, Guru dan orang tua di semua tingkatan kelas sepakat pada tiga nilai karakter yang paling penting untuk pembelajaran.tiga karakter tersebut adalah sebagai berikut: (1) menghormati diri sendiri dan orang lain, (2) kejujuran, dan (3) kontrol diri/disiplin. Dan tiga poin yang paling utama adalah sebagai berikut: 
ketekunan, (2) motivasi, dan (3) empati. (Cletus R. Bulach: 2000).

Dengan demikian diharapkan pengembangan pendidikan karakter pada siswa di sekolah dapat dikembangkan dengan menggunakan bantuan atau layanan dalam bimbingan dan konseling, mengingat bahwa tujuan utama dari layanan konseling adalah untuk mengembangkan potensi yang ada pada siswa.

\section{PEMBAHASAN}

\section{Pendidikan Karakter}

Karakter merupakan ciri khusus yang melekat pada seseorang, keluarga, dan komunitas. Karakter adalah konsisten dan dapat diprediksi ditunjukkan oleh kecenderungan perilaku. Perilaku tidak berdiri sendiri, tetapi terintegrasi dengan sikap dan nilai-nilai (Lapsley, DK \& Narvaez, D., 2006). Pengembangan karakter dimulai dari pembentukan sikap berdasarkan nilai-nilai tertentu, seperti nilai-nilai agama, budaya, termasuk ideologi negara. Karakter seseorang bukanlah hasil dari penilaian terhadap sikap dan perilaku diri sendiri, tetapi merupakan hasil dari penilaian orang lain. Karakter tidak dilahirkan dari retorika mulia atau niat baik semata, tetapi karakter lahir dari kejujuran dan loyalitas yang melekat pada nilai-nilai moral (Josephson. M, 2013).

Pendidikan karakter, konsep pengembangan kesadaran moral pada siswa (LicNona, 1999), muncul dari psikologis, pembelajaran sosial, dan kerangka berpikir perkembangan kognitif. Sebuah tinjauan literatur mengungkapkan keprihatinan dalam menemukan pendekatan yang paling mujarab untuk mengembangkan karakter siswa. Studi dalam pendidikan karakter telah dilakukan di bidang perkembangan kognitif (Gibbs 2006; Narvaez, 2001); kebajikan karakter (LicNona, 1999); dan pembelajaran sosial (Anderson, 2000; Wynne, 1997). Pendekatan perkembangan berteori bahwa anak-anak mengembangkan moral secara bertahap. Teori ini dikembangkan oleh Lawrence Kohlberg dan mirip dengan model yang dikembangkan oleh Jean Piaget (Kohlberg, 1989).

Para ahli menafsirkan pendidikan karakter dalam berbagai perspektif, untuk contoh, pendidikan karakter berasal dari tahap pembentukan karakter (Marten, 2004), dimensi psikologis (LicNona, 1991), penilaian moral (Piaget, 1967; Kohlberg; 1976), dan pedagogis pendekatan (Berkowitz, 2002). Marten (2004) menjelaskan bahwa ada tiga tahapan yang harus dilakukan dalam pendidikan karakter, yaitu identifikasi nilai-nilai, nilai pembelajaran dan memberikan kesempatan untuk menerapkan nilai tersebut. Pendidikan karakter psikologis meliputi penalaran moral dimensi, perasaan moral, dan perilaku moral (LicNona, 1991), atau dalam arti moralitas yang mencakup utuh sebagai pertimbangan moral dan perilaku moral baik moralitas yang berdasarkan pada orientasi dan perkembangan moralitas sosial (Piaget, 1967; Kohlberg; 1976).

\section{Konseptualisasi Karakter Pribadi}

Pendidikan Karakter yang mengacu pada judul kurikulum yang mendidik siswa tentang seperti peduli, kewarganegaraan, keadilan, rasa hormat, tanggung jawab, dan kepercayaan. Pusat Kurikulum Departemen Pendidikan (Menteri Pendidikan Nasional 2010) menyatakan bahwa untuk lebih memperkuat pelaksanaan pendidikan karakter di satuan pendidikan Indonesia 
telah mengidentifikasi 18 nilai-nilai yang berasal dari agama, Pancasila (ideologi nasional), budaya, dan tujuan pendidikan nasional, yaitu :

- Agama: Sikap dan perilaku taat dalam melaksanakan ajaran agama mereka, praktek. agama toleran terhadap orang lain, dan hidup harmonis dengan agama-agama lain.

- Jujur: perilaku yang berdasarkan pada upaya untuk sesuai dirinya sebagai orang yang selalu dapat dipercaya dalam kata, tindakan, dan pekerjaan.

- Toleransi terhadap Keanekaragaman: Sikap dan tindakan yang menghormati perbedaan agama, ras, etnis, pendapat, sikap, dan tindakan orang lain yang berbeda dari diri mereka sendiri

- Disiplin: Tindakan yang menunjukkan perilaku tertib dan mematuhi berbagai aturan dan peraturan

- Kerja keras: Tindakan yang menunjukkan tertib perilaku dan mematuhi berbagai aturan dan peraturan.

- Kreatif: menipis dan melakukan sesuatu untuk menghasilkan cara baru atau hasil dari sesuatu yang telah diselenggarakan

- Independen: Sikap dan perilaku yang tidak mudah tergantung pada orang lain untuk menyelesaikan tugas

- Demokrat: Cara individu dalam berperilaku, dan bertindak hak yang sama dan kewajiban menilai dirinya dan orang lain

- Curiosity: Sikap dan tindakan sebagai mencoba untuk menentukan kedalaman dan penyebaran sesuatu yang dipelajari, dilihat, dan didengar.
- Semangat Kebangsaan: tindakan, dan suara yang menempatkan kepentingan bangsa dan negara di atas diri sendiri dan kepentingandan kelompok

- Cinta Tanah Air: tindakan, dan suara yang menempatkan kepentingan bangsa dan negara di atas diri sendiri dan menghargai kelompok

- Prestasi: Sikap dan tindakan yang mendorong dirinya untuk menghasilkan sesuatu yang berguna bagi masyarakat, mengakui dan menghormati keberhasilan orang lain.

- Ramah / Komunikatif: Sikap dan tindakan yang mendorong dirinya untuk peduli dan lebih aktif terhadap orang lain.

- Cinta Perdamaian: Sikap dan tindakan yang mendorong dirinya untuk cinta akan kedamaian yang ada di lingkungannya.

- Gemar Membaca: Kebiasaan untuk membaca berbagai bacaan yang memberikan kebajikan bagi dirinya

- Peduli Lingkungan: Sikap dan tindakan yang dilakukan untuk mencegah kerusakan alam lingkungan sekitarnya, dan mengembangkan upaya-upaya untuk mencoba dan untuk memperbaiki kerusakan lingkungan yang telah terjadi

- Kepedulian Sosial: Sikap dan tindakan selalu ingin anggota membantu orang lain dan masyarakat yang membutuhkan.

- Tanggung Jawab: Sikap dan perilaku seseorang untuk melaksanakan tugas dan kewajibannya, yang harus dilakukan, terhadap diri sendiri, masyarakat, lingkungan (alam, sosial, dan budaya), Negara dan Tuhan Yang Maha Esa. 


\section{Layanan Bimbingan dan Konseling}

Bimbingan dapat diartikan sebagai sesuatu proses pemberian bantuan kepada individu yang dilakukan secara berkesinambungan, supaya individu tersebut dapat memahami dirinya sendiri, sehingga dia sanggup mengarahkan dirinya dan dapat bertindak secara wajar, sesuai dengan tuntutan dan keadaaan lingkungan sekolah, keluarga, masyarakat dan kehidupan pada umumnya, Bimbingan membantu individu mencapai perkembangan diri secara optimal sebagai makhluk sosial. Konseling merupakan suatu upaya bantuan yang dilakukan dengan empat mata atau tatap mukaantara konselor, dan konseli yang berisi usaha yang selaras, unik, human (manusiawi), yang dilakukan dalam suasana keahlian dan yang didasarkan atas normanorma yang berlaku, agar konseli memperoleh konsep diri dan kepercayaan diri sendiri dalam memperbaiki tingkah lakunya saat ini dan mungkin pada masa yang akan datang.

Secara umum tujuan pelaksanaan layanan bimbingan dan konseling adalah berupaya membantu siswa menemukan pribadinya, dalam hal mengenal kekuatan dan kelemahan dirinya, serta menerima dirinya secara positif dan dinamis sebagai modal pengembangan diri lebih lanjut. Jenis layanan bimbingan dan konseling terselenggara harus sesuai dengan empat bidang bimbingan yaitu: (1). Bidang bimbingan Pribadi (2). Bidang bimbingan sosial (3). Bidang bimbingan belajar (4). Bidang bimbingan karier. (Nur Kholis: 2015).

\section{Implementasi Pendidikan Karakter Melalui Pelayanan BK di Sekolah}

Penerapan pendidikan karakter juga diharapkan tidak akan terlepas dari pelayanan BK di sekolah. Pelayanan BK di sekolah merupakan salah satu layanan yang juga dapat memberikan perubahan pada perkembangan dan kemampuan peserta didik, baik dalam proses belajar mengajar, religius, sosial, dan karir dari peserta didik itu sendiri.

Implementasi pendidikan karakter malalui pelayanan $\mathrm{BK}$ di sekolah, diharapkan mampu untuk meningkatkan nilai-nilai karakter yang ada pada peserta didik/siswa. Karena dalam pelayanan BK itu sendiri sudah menekankan pada empat bidang layanan, yaitu pribadi, sosial, belajar dan karir. Sedangkan dalam pendidikan karakter juga lebih menekan kan pada nilainilai yang terdiri dari 18 nilai-nilai dan terdiri dari 4 dimensi perkembangan. Pendidikan karakter jauh lebih mungkin untuk bekerja ketika itu dirancang dengan baik, ketika hal itu bergantung pada prinsipprinsip berbasis penelitian dan kerangka konseptual bermakna, dan ketika itu sepenuhnya dan akurat dilaksanakan.

Dalam pendidikan (1) karakter pendek dapat bekerja dan sering melakukan, (2) dampak pendidikan karakter yang efektif berbagai kognitif siswa, afektif, perilaku, dan hasil akademik, dan (3) kita dapat mengidentifikasi aspek-aspek tampaknya sangat terkait dengan efektivitas. Jadi mari kita memeriksa apa yang kita ketahui tentang karakteristik pendidikan karakter yang efektif. Pengembangan profesional. Mengingat kompleksitas, masuk akal bahwa untuk mencoba untuk menerapkan budaya sekolah yang 
komprehensif dan reformasi pedagogis tanpa pelatihan yang memadai tidak mungkin menjadi terlalu sukses dalam penerapan pendidikan karakter pada peserta didik. Semua program pendidikan karakter yang efektif termasuk setidaknya opsional pengembangan profesional. Kepemimpinan. Sebuah bukti-bukti telah memusatkan perhatian pada pentingnya kepemimpinan sekolah dalam pendidikan karakter, dan perubahan sekolah dan reformasi pada umumnya. Pemimpin sekolah yang benarbenar perlu menghargai pendidikan karakter, memahami secara mendalam apa yang memerlukan, dan memiliki kompetensi untuk menjadi pendidikan karakter pemimpin instruksional.

Selain pemimpin sekolah, konselor juga memberikan dampak perubahan terhadap manajemen perubahan di sekolah, seperti pengembangan budaya dan kepemimpinan sekolah dalam PPK (Penguatan Pendidikan Karakter) fungsi transformatif kepala sekolah. Selain itu, ada banyak alasan untuk berinvestasi dalam pendidikan karakter. Namun, apa pun alasannya, itu harus menjadi bagian dari misi utama sekolah. Terlalu banyak misi yang gerak tubuh hanya berperan untuk memeriksa dari satu kewajiban lagi, dan tidak ada hubungannya dengan mengarahkan kehidupan sekolah. Sebelas Prinsip CEP Pendidikan Karakter Efektif menyoroti titik bahwa pendidikan karakter harus tercermin dalam semua aspek kehidupan sekolah. Charles Elbot dan David Fulton The Disengaja Budaya Sekolah (2008) menawarkan panduan lengkap untuk bagaimana sekolah bergerak melalui tahapan membangun inisiatif misi-driven yang komprehensif.
Guru Bimbingan dan Konseling atau Konselor bertanggung jawab atas kegiatan pembelajaran yang terkait dengan pelayanan BK untuk sejumlah peserta didik. Oleh sebab itu, disekolah harus diadakan pelayanan bimbingan dan konseling. Tujuan pelayanan bimbingan dan konseling adalah agar konseli dapat merencanakan kegiatan penyelesaian studi, perkembangan karir serta kehidupannya di masa depan, mengembangkan seluruh potensi dan kekuatan yang dimilikinya seoptimal mungkin, menyesuaikan diri dengan lingkungan, mengatasi hambatan dan kesulitan yang dihadapi serta pengembangkan karakter secara maksiamal. Adapun manfaat pengembangan karakter melalui layanan bimbingan dan konseling ini ialah : (1) agar siswa lebih mandiri dalam menyelesaikan masalahnya, (2) agar siswa lebih bisa menerapkan sopan santun yang baik di kalangan masyarakat, (3) agar siswa bias menghargai setiap proses belajar yang mereka alami baik di sekolah maupun di rumah, dan (4) agar siswa lebih bisa memahami dirinya dengan baik. (Prasetyo, dkk, 2017)

Selain itu, penerapan pendidikan karakter juga tersusun atas tiga bagian, seperti yang dijeskan oleh (Zubaedi, 2011: 13 dalam Ramdhani, 2014) yakni: moral knowing (pengetahuan moral), moral feeling (perasaan moral), dan moral behavior (perilaku moral). Karakter yang baik terdiri dari pengetahuan tentang kebaikan (knowing the good), keinginan terhadap kebaikan (desiring the good), dan berbuat kebaikan (doing the good). Dalam hal ini, diperlukan pembiasaan dalam pemikiran (habits of the mind), dan pembiasaan dalam tindkan (habits of the heart), dan pembiasaan dalam tindakan 
(habit of the action). Tentunya bagian ini juga sesuai dengan tujuan dari perkembangan dan layanan dalam bimbingan dan konseling.

Namun demikian, masih banyak ditemukan dilapangan bahwa Implementasi pendidikan karakter belum menyentuh dimensi penghayatan afektif dan masih jauh dari tataran pengamalan nilai secara nyata dalam tindak perilaku hidup terpelajar sehari-hari. Konsep dasar yang dipergunakan sebagai orientasi pendidikan karakter di Indonesia juga tidak jelas ujung pangkalnya. Dari mana berangkatnya dan mau ke mana pendidikan karakter dibawa, landasan filosofisnya tidak mudah ditemukan. Arthur (2014:205) mengamati bahwa gerakan pendidikan karakter ini tidak memiliki perspektif teoretis dan dasar praktek bersama. (dalam Barus, 2015).

Dengan penjelasan di atas maka dapat dipahami bahwa implementasi pendidikan karakter dapat dilakukan dengan mengguanakan layanan dalam bimbingan dan konseling yang tentunya tetap menuntut pada perubahan atau perkembangan dari nilai-nilai karakter yang dimiliki oleh peserta didik dan berfokus memang hanya pada perubahan prilaku kearah yang lebih positif dan optimal. Selain itu dalam layanan bimbingan dan konseling juga menekankan pada peruabahan tingkah laku atau prilaku dari peserta didiknya dalam menghadapi setiap permasalahan yang mereka hadapi. Walupun dalam implementtasinya masih banyak sekolah atau lembaga pendidikan yang belum terlalu paham dan mengerti dari mana awal mulanya akan di kembangakan dan dibentuk pendidikan karakter.

\section{PENUTUP}

Seperti yang diharapkan oleh pemerintah Indonesia bahwa pelaksanaan kurikulum baru bernama Kurikulum 2013 yang menekankan perlunya pendidikan di sekolah-sekolah untuk mengembangkan sumber daya manusia yang pengetahuan, pemahaman dan memiliki karakter yang kuat. Untuk tujuan ini, beberapa sekolah tinggi telah dipilih untuk menerapkan kurikulum baru ini sebagai sekolah percontohan; mereka telah menerapkan program pendidikan karakter. (Rahmi Fahmyak: 2015)

Implementasi pendidikan karakter malalui pelayanan BK di sekolah, diharapkan mampu untuk meningkatkan nilai-nilai karakter yang ada pada peserta didik/siswa. Karena dalam pelayanan BK itu sendiri sudah menekankan pada empat bidang layanan, yaitu pribadi, sosial, belajar dan karir. Sedangkan dalam pendidikan karakter juga lebih menekan kan pada nilainilai yang terdiri dari 18 nilai-nilai dan terdiri dari 4 dimensi perkembangan yaitu oleh pikir, olah hati, olah karsa dan olah raga. Pendidikan karakter jauh lebih mungkin untuk bekerja ketika itu dirancang dengan baik, ketika hal itu bergantung pada prinsip-prinsip berbasis penelitian dan kerangka konseptual bermakna, dan ketika itu sepenuhnya dan akurat dilaksanakan. Selain diharapkannya peran konselor, Guru dan orang tua di semua tingkatan kelas sepakat pada tiga nilai karakter yang paling penting untuk pembelajaran.tiga karakter tersebut adalah sebagai berikut: (1) menghormati diri sendiri dan orang lain, (2) kejujuran, dan (3) kontrol diri / disiplin. Dan tiga poin yang paling utama adalah sebagai berikut: (1) ketekunan, (2) motivasi, 
dan (3) empati. (Cletus R. Bulach: 2000).

\section{REFERENSI}

Akbar K Setiawan. (2011). Integrasi Pendidikan Karakter Dalam Pembelajaran Berbasis Interkultural. Fbs Universitas Negeri Yogyakarta

Anderson, D. (2000). Character Education: who is responsible? Journal of Instructional Psychology, 27(3), 139

Arthur, J. dalam Larry P. Nucci \& Darcia Nar- vaez. 2014. Handbook Pendidikan Moral dan Karakter. Bandung: Nusa Media.

ASCA-American School Counselor Association (2007). Careers / Roles. Retrieved January 4, 2007, from http://www.schoolcounselor.org. Baysal, A. (2004).

Berkowitz, M.W. (2002). The science of character education. In W. Damon (Ed.), Bringing in a new era in character education (pp. 43-63). Standford CA. Hoover Institution Press.

Budi Prasetyo, Heny Apriani Dan Beny Dwi Pratama, 2017, Pengembangan Pendidikan Karakter Melalui Pelayanan Bimbingan Dan Konseling, Prosiding Snbk (Seminar Nasional Bimbingan Dan Konseling) Vol. 1 No.1 (Mei 2017) Online Issn 2580-216x.

Bulach, C. R. (2000). Bullying behavior at the middle school level: Are there gender differences? Paper presented at the American Educational Research Association at New Orleans, LA, 4-27-2000

Bulach, C. R. (2000). External factors that affect bullying behavior. Paper presented at theEastern Educational
Research Association at Clearwater, FL, 2-17-2000.

Elbot, C. F., \& Fulton, D. (2008). Building an intentional school culture: Excellence in academics and character. Thousand Oaks, CA: Corwin.

Gendon Barus, 2015, Menakar Hasil Pendidikan Karakter Terintegrasi Di Smp, Cakrawala Pendidikan, Juni 2015, Th. Xxxiv, No. 2

Gibbs, J. (2006). Should Kohlberg's cognitive developmental approach to morality be replaced with a more pragmatic approach? Comments on Krebs and Denton (2005). Psychological Review, 22 (3), 666667.

Josephson, M. (2003), Josephson Institute of Ethics and Character Counts, www.josephsonInstitute.org

(Diakses tgtl 10 sep.2013)

Kementrian Pendidikan Nasional. (2010). Pembangunan Pendidikan Budaya dan Karakter Bangsa: Pedoman Sekolah. Jakarta: Puskur Balitbang Kemendiknas.

Kohlberg, L. (1976). "Moral Stages and Moralization. The CognitiveDevelopmental Approach." Moral Development and Behavioral: Theory, Research and Issue, Thomas Lickona (ed) News York: Holt, Rinehart, Winston

Kuhn, L. (2004). Student Perceptions of School Counselor Roles and Functions. $\mathrm{s}$ thesis. University of Maryland, Baltimore. Kuzgun, Y. mesleki g development in elementary school). (Y. Kuzgun, Ed.) (pp.125-15 
Lapdley, D.K \& Narvaez, D. (2006). Character education. In Vol 4 (A. Renninger \& I. Siegal, volume Eds.). Handbook of Child Psychology (Damon \& R. Lerner, SSeries Eds.) (pp. 248-296). Newww York: Wiley.

Lickona, T. (2004). Character Matters. New York, NY: Simon \& Schuster

Licnona, Thomas. (1999). Characteer Education: The cultibation of Virtue. In C. M. Reigeluth (Ed.), Instructional-design theories and models: A new paradigm of instructional theory (pp. 594-612).

Mahwah, NJ: Lawrence Erlbaum Associates

Lickona,T. (1991). Educating for character:How our schools can teach respect and responsibility.New York: Bantam Books, 51

Marten, R. (2004). Successful Coaching, 3th edition, Champaign, IL: Human kinetics

Morrissette, P. (2000). School counselor well-being. Guidance and Counseling, 16 (1), 2-9.

Muhammad Ali Ramdhani, 2014, Lingkungan Pendidikan Dalam Implementasi Pendidikan Karakter, Jurnal Pendidikan Universitas Garut, Vol. 08; No. 01; 2014; 28-37, Issn: 1907-932x

Myrick, RD (2003). Developmental guidance and counseling: a practical approach. Minneapolis:Educational Media Corporation.(Perceptions and evaluations of teachers on comprehensive/developmental guidance and psychological counseling programs)., 10, 132-145. s sl 10 (18), 1-17.

Narvaez, D. (2001). Moral text comprehension: Implications for education and research Journal of Moral Education, 30(1), 43-54

Nur Kholis , (2015). Pelaksanaan Layanan Bimbingan Dan Konseling. Pendidikan Bimbingan dan Konseling: Semarang

Paisley, PO \& Mc Mahon, HG (2001). School counseling for the 21.st century: challenges and oppurtunities. Professional School Counseling, 5 (2), 106-116.

Piaget, J. (1967/1971). Biology and knowledge: an essay on the relation between organic regulation and cognitive processes. Chicago: University of Chicago Press.

Rahmi, Dkk. (2015). Measuring Student Perceptions to Personal Characters Building in Education: An Indonesian Case in Implementing ew Curriculum in High School. Procedia - Social and Behavioral Sciences 211 ( 2015 ) $851-858$. Padang. Indonesia

Sidiknas Uu No 20 Tahun 2003

Wynne, E. (1997). For Character education. In A. Molnar (Ed), The Construction of Children's character The construction of children's character. Ninety-sixth yearbook of the national society for the study of education (pp. 63-76). Chicago, IL: University of Chicago Press.

Zubaedi. (2011). Desain Pendidikan Karakter: Konsepsi dan Aplikasinya dalam Lembaga Pendidikan. Jakarta: Kencana. 